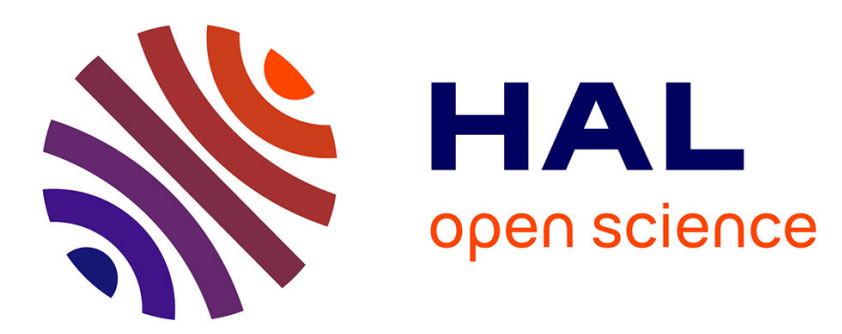

\title{
Fluorogenic squaraine dendrimers for background-free imaging of integrin receptors in cancer cells
}

\author{
Pichandi Ashokkumar, Mayeul Collot, Andrey S Klymchenko
}

\section{To cite this version:}

Pichandi Ashokkumar, Mayeul Collot, Andrey S Klymchenko. Fluorogenic squaraine dendrimers for background-free imaging of integrin receptors in cancer cells. Chemistry - A European Journal, 2021, 27 (22), pp.6795-6803. 10.1002/chem.202100480 . hal-03431727

\section{HAL Id: hal-03431727 \\ https://hal.science/hal-03431727}

Submitted on 16 Nov 2021

HAL is a multi-disciplinary open access archive for the deposit and dissemination of scientific research documents, whether they are published or not. The documents may come from teaching and research institutions in France or abroad, or from public or private research centers.
L'archive ouverte pluridisciplinaire HAL, est destinée au dépôt et à la diffusion de documents scientifiques de niveau recherche, publiés ou non, émanant des établissements d'enseignement et de recherche français ou étrangers, des laboratoires publics ou privés. 


\title{
Fluorogenic squaraine dendrimers for background-free imaging of integrin receptors in cancer cells
}

\author{
Pichandi Ashokkumar, ${ }^{[a],[b]}$ Mayeul Collot, ${ }^{*[a]}$ and Andrey S. Klymchenko*[a]
}

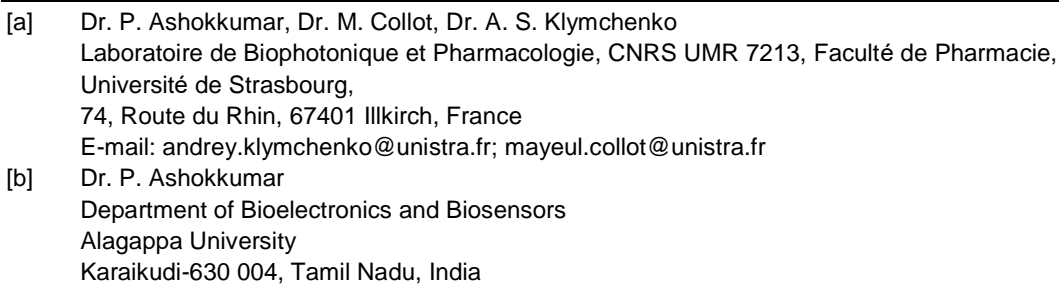

Supporting information for this article is given via a link at the end of the document.

\begin{abstract}
To overcome the limited brightness of existing fluorogenic molecular probes for biomolecular targets, we introduce a concept of fluorogenic dendrimer probe, which undergoes polarity-dependent switching due to intramolecular aggregation-caused quenching of its fluorophores. Based on a rational design of dendrimers with four and eight squaraine dyes, we found that octamer bearing dyes through a sufficiently long PEG(8) linker displays $>400$-fold fluorescence enhancement from water to non-polar dioxane. High extinction coefficient $\left(\sim 2,300,000 \mathrm{M}^{-1} \mathrm{~cm}^{-1}\right)$ resulted from eight squaraine dyes and quantum yield ( 25\%) make this octamer the brightest environment-sensitive fluorogenic molecule reported to date. Its conjugate with cyclic RGD used at low concentration ( $3 \mathrm{nM}$ ) enables integrin-specific fluorescence imaging of cancer cells with high signalto-background ratio. The developed dendrimer probe is a "golden middle" between molecular probes and nanoparticles, combining small size, turn-on response and high brightness, important for bioimaging
\end{abstract}

\section{Introduction}

Despite rapid advances of fluorescence bioimaging techniques, their performance relies on development of smart fluorescent probes. ${ }^{[1]}$ An ideal fluorescent probe should exhibit high brightness (expressed as extinction coefficient $\times$ quantum yield), good photostability and ideally excitable at far-red to nearinfrared wavelengths in order to minimize phototoxicity and unwanted auto-fluorescence background. Another important criterion is the fluorogenic nature of the probe, that is the capacity to light up only in response to a specific target or event. ${ }^{[2]}$ Since such probes are practically non-fluorescent in their free form, they can drastically decrease the background and thus improve the signal-to-background ratio in fluorescence imaging under nowash conditions..$^{[2-3]}$ Moreover, fluorogenic probes become increasingly popular in super-resolution microscopy. ${ }^{[1 \mathrm{~b}, 4]}$ Various design strategies have been employed for the generation of fluorogenic probes, ${ }^{[5]}$ which can be classified into two classes: (i) environment-sensitive dyes that undergo light up on target binding ${ }^{[2 a]}$ and (ii) chemical reaction-based fluorophore restoration from a quenched state. ${ }^{[2 b, 6]}$ Environment-sensitive dyes operate by various mechanisms, excited state charge transfer (solvatochromic dyes), ${ }^{[7]}$ excited state intramolecular proton transfer (ESIPT probes), ${ }^{[8]}$ twisted intramolecular charge transfer
$(\mathrm{TICT}),{ }^{[9]}$ rotation induced quenching in molecular rotors, ${ }^{[10]}$ Motion-Induced Change in Emission (MICE), ${ }^{[1]}$ and aggregationcaused quenching $(\mathrm{ACQ})^{[12]}$ and aggregation-induced emission (AIE). ${ }^{[13]}$ These environment-sensitive fluorogenic probes were particularly suitable to study ligand-receptor interactions at the membrane level, where the binding event is associated with dramatic decrease in the local polarity and increase in the local viscosity. ${ }^{[2 a, 12,14]}$ However, environment-sensitive probes exhibit limited brightness, with extinction coefficient rarely reaching $100,000 \mathrm{M}^{-1} \mathrm{~cm}^{-1}$ and quantum yields well below unity. [2a]

To overcome this fundamental limitation, one approach is to combine multiple high-performance fluorophores in a single molecular probe, undergoing ACQ. This approach was initially realized for polymers bearing multiple self-quenched Cy5.5 dyes that light up through the enzymatic cleavage. ${ }^{[15]}$ Environmentsensitive fluorogenic dyes operating by ACQ mechanism were realized in case of dye dimers in exciton-controlled hybridizationsensitive fluorescent oligonucleotide $(\mathrm{ECHO})$ probes. ${ }^{[16]}$ Later on, to obtain bright fluorogenic probes for target receptors, we developed a squaraine (SQ) dimer probe, which displayed polarity-dependent formation/disruption of intramolecular $\mathrm{H}$ aggregates. ${ }^{[17]}$ This probe enabled imaging G-protein coupled receptor (oxytocin) with high signal to background ratio in washfree conditions ${ }^{[17]}$ as well as to detection of biotin receptors in cancer cells. ${ }^{[18]}$ The concept was extended to near-infrared cyanine 5.5 dyes for in vivo imaging of natively expressed oxytocin receptors in live mice ${ }^{[19]}$ and to rhodamine-based dimers to light up RNA aptamers in live cells. ${ }^{[20]}$ However, it remains unclear whether environment-sensitive dyes operating by ACQ principle can be designed using dendrimer systems, ${ }^{[21]}$ which can combine larger number of dyes. Bright fluorescent dendrimers have been previously reported, ${ }^{[22]}$ and they have demonstrated potential in light-harvesting ${ }^{[23]}$ and biomedical applications. ${ }^{[24]}$ Fluorescent dendrimers have also been used to amplify signal of reporter dyes by energy transfer in biosensing and bioimaging. ${ }^{[25]}$ However, design of environment-sensitive fluorogenic dendrimer systems with a light up on recognition of biomolecular targets has not been explored so far.

An attractive target receptor for imaging cancer cells is $\alpha_{v} \beta_{3}$ integrin that is overexpressed on the surface of carcinoma cells and tumour blood vessels ${ }^{[26]}$ and ensures resistance of tumours to therapies. ${ }^{[27]}$ As integrins regulate a diverse array of cellular functions crucial to the initiation, progression and metastasis of solid tumours, it is widely used as targets for the design of specific 
therapeutics and imaging bio-markers to validate the efficacy of anti-angiogenic and anti-tumour agents. ${ }^{[28]}$ One of the most effective ligands to target $\alpha_{v} \beta_{3}$ integrin is cyclic peptide containing an Arg-Gly-Asp-D-Phe-Lys sequence, c(RGDfK). ${ }^{[29]}$ So far, a number of RGD conjugated fluorescent probes have been employed by using organic dyes ${ }^{[30]}$ and inorganic complexes. ${ }^{[31]}$ Moreover, RGD derivatives have been extensively used in much larger fluorescent structures, such as nanoparticles, ${ }^{[32]}$ which indicates that they are robust integrin-targeting ligands for entities of different size. However, most of the probes lack fluorogenecity to enable wash-free imaging in live cells.

In the present work, we propose a concept of environmentsensitive fluorogenic dendrimer, where a large number of fluorophores respond to the environment polarity by intramolecular aggregation/disaggregation, yielding fluorogenic molecular probes of outstanding brightness: extinction coefficient of $\sim 2,300,000 \mathrm{M}^{-1} . \mathrm{cm}^{-1}$ and quantum yield of $25 \%$. The developed tetrameric and octameric squaraine-based dendrimers were effectively quenched in water due to their collapsed selfquenched forms, and light up in organic solvent due to dendrimer expansion and thus dye dis-assembly. A rational design of the octamer, where the dyes are connected to the dendrimer core through a sufficiently long PEG(8) linker, led to an optimized fluorogenic module exhibiting $>400$-fold fluorescence enhancement between water and non-polar solvent. Its conjugate with cyclic RGD led to receptor-specific wash-free imaging of cancer cells with high signal to background ratio. The developed dendrimer constitutes a unique platform for background free imaging, combining 8-fold higher brightness than organic dyes with relatively small size compared to luminescent nanoparticles.

\section{Results and Discussion}

\section{Design and Synthesis}

We hypothesized that dendrimer fluorophores may exhibit different intramolecular dye-dye aggregation states as a function of solvent. In water, hydrophobic interactions within low polar $S Q$ dyes should drive formation of non-emissive aggregates (collapsed OFF state, Scheme 1A), similar to that observed before for fluorogenic dimers. ${ }^{[17-20]}$ Then in organic media or in the low polar environment of the target membrane receptor, the dendrimer would switch from the collapsed state to the expanded state, where dyes are well separated from each other leading to the highly emissive dendrimer (ON state, Scheme 1A). To verify this hypothesis, we synthesized three dendrimer SQ dyes: SQ-tet, SQ-oct and SQPEG-oct as well as a control monomeric SQ-OH (Scheme 1B). SQ fluorophore was selected because, it is characterized by high brightness ${ }^{[33]}$ and photostability, ${ }^{[34]}$ as well as capacity to form non-fluorescent $\mathrm{H}$-aggregates, ${ }^{[35]}$ used in fluorogenic dimers. ${ }^{[17-18,36]}$ Using L-lysine, we first prepared dendrimers Lys-tet and Lys-oct, bearing four and eight amino groups, respectively, and one acetylene group grafted at the core L-lysine carboxylate (Scheme 2). The amino groups were then used to graft $S Q$ fluorophores through carbamide chemistry to yield tetrameric and octameric $S Q$ derivatives. To design $S Q$ dye unit (SQ-OH), one end of $S Q$ was substituted with a PEG(4) chain to minimize nonspecific interactions of the dye moieties in biological media. ${ }^{[14 a, 17,37]}$ The other end was modified with a $C(6)$ hydrocarbon linker bearing hydroxyl group for grafting to the dendrimer. The SQ-OH dye was transformed into an activated carbamate (4) for further coupling with the dendrimer amines, yielding tetrameric (SQ-tet) and octameric (SQ-oct) dendrimers. Moreover, a longer hydrophilic PEG(8) linker was also introduced into the $S Q$ dye. We hypothesized that this longer linker could reduce the hydrophobic nature of the dendrimer and could improve the capacity of the latter to respond to the environment by taking the fluorophores further away from each other in the expanded configuration (in the ON state, see Scheme 1A). For this purpose dye 4 was reacted with $\mathrm{NH}_{2}-\mathrm{PEG}(8)-\mathrm{OH}$, affording SQPEG, then converted into the activated carbamate 6 and, finally coupled with Lys-oct yielding dendrimer dye SQPEG-oct (Scheme 1). The latter was functionalized with a cyclic RGD targeting ligand by Cu-catalysed click reaction with $\mathrm{c}(\mathrm{RGDfK})$ azide to give final probe SQPEG-oct-RGD. In addition, a control monomeric dye-RGD conjugate (SQPEG-RGD) was obtained by reacting 6 with peptide $c(R G D f K)$. 


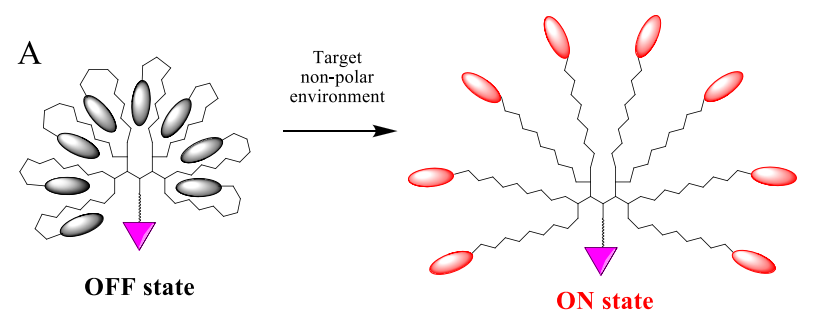

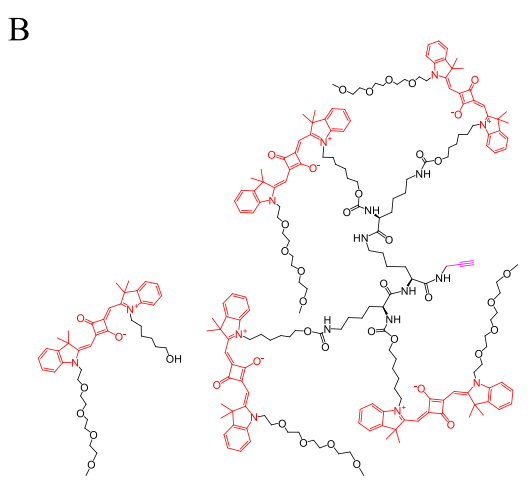

SQ-OH
ON state

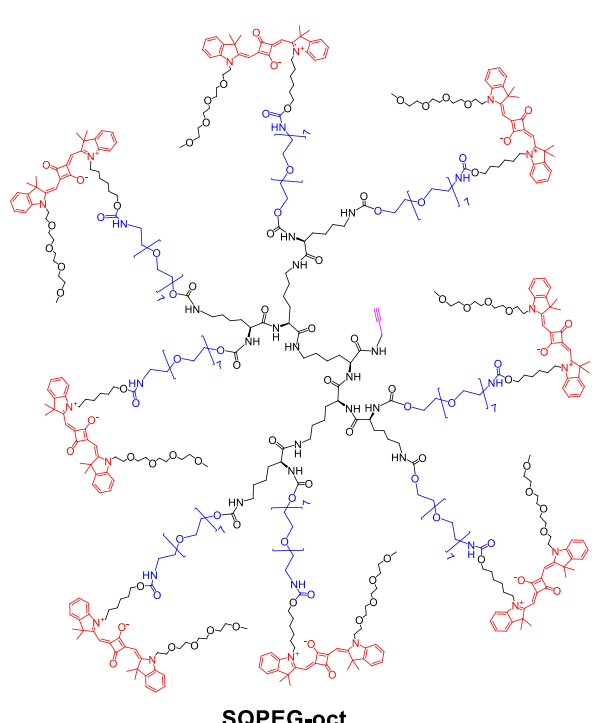

SQ-oct

SQPEG-oct

Scheme 1. Fluorogenic dendrimers. Principle of fluorogenic response of the octamer: collapsed OFF state is transformed in the target environment into expanded ON state (A). Chemical structures of squaraine dye monomer (SQ-OH), tetramer (SQ-tet) and octamers (SQ-oct and SQPEG-oct) (B). 


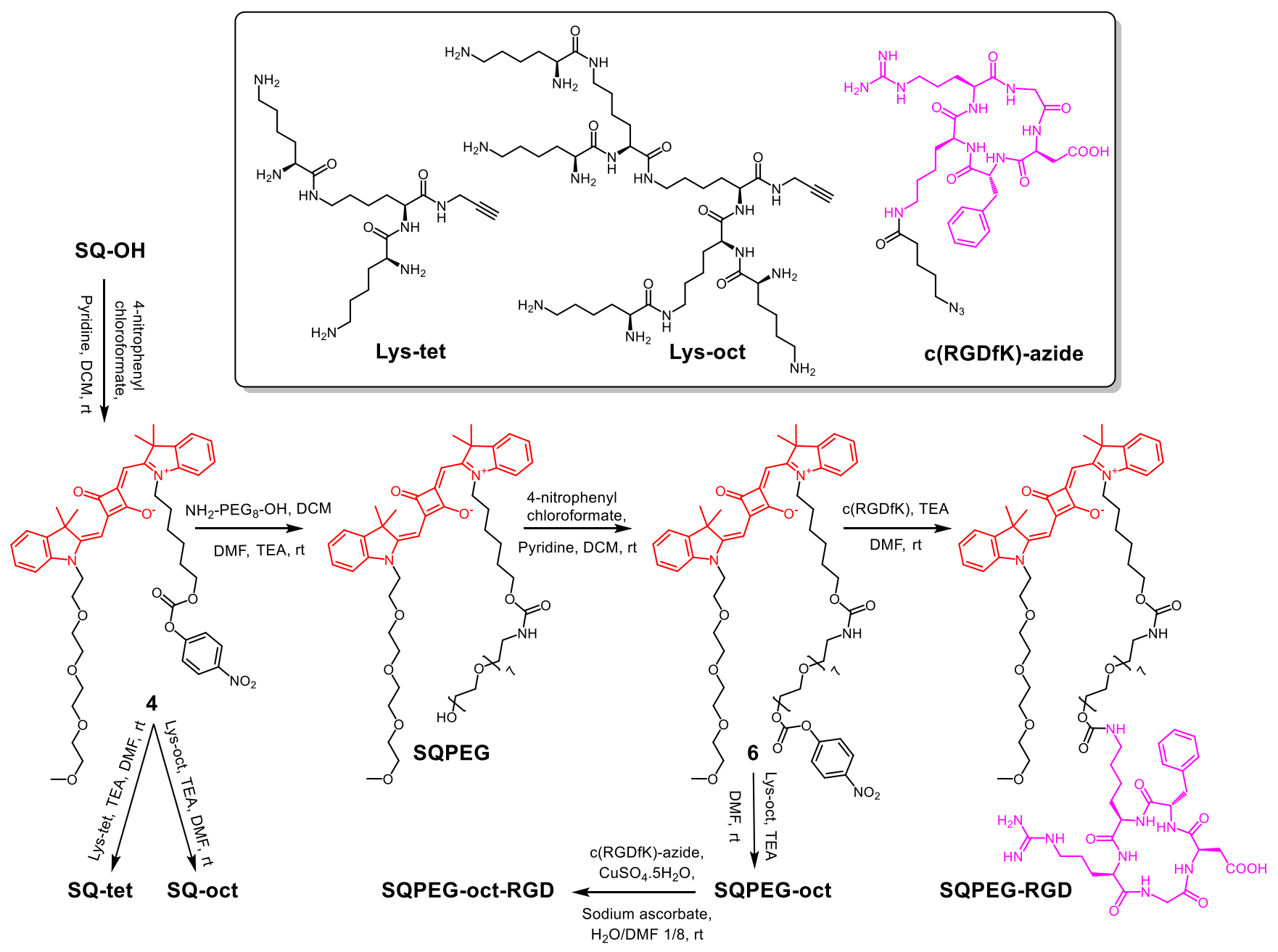

Scheme 2. Synthesis of SQ dyes, SQ tetramer and octamers and their conjugates with RGD ligand.

\section{Photophysical characterization in solvents}

The spectroscopic properties of the monomeric dyes (SQ-OH, SQPEG, SQPEG-RGD), tetramer (SQ-tet), octamer (SQ-oct) and PEGylated octamer (SQPEG-oct, SQPEG-oct-RGD) were studied in various solvents of increasing polarity (Figure 1, Table 1; Figure S1-S3 and Table S1 in SI). In organic solvents, including dioxane, all the dyes showed a similar single sharp absorption band around $640 \mathrm{~nm}$ (Figure 1A, Figure S1). By contrast, in aqueous medium, the absorption spectra of dendrimers were markedly different from those of monomers (Figure 1B, Table S1). Monomer dyes SQ-OH and SQPEG displayed a single absorption band at 628-629 nm, whereas tetramer and octamer derivatives showed an additional absorption band at shorter wavelengths $(592-605 \mathrm{~nm})$. Their main absorption band was broader and shifted to the red $(\sim 640 \mathrm{~nm})$ compared to the monomers. (Figure 1B). To understand better this phenomenon, we studied the excitation spectra recorded at the dye emission maximum (Figure S2). For monomeric dyes SQ-OH and SQPEG, the excitation spectra were similar to those of their absorption spectra (Figure 1C). By contrast, the excitation spectra of dendrimer dyes (SQ-tet and SQPEG-oct and SQPEG-oct-RGD) were different from their absorption spectra, but they matched well with the excitation spectrum of SQ-OH in water. This excitation spectrum corresponds to the small fraction of the emissive species, while the short-wavelength band and the main broad red shifted absorption band correspond to non- emissive aggregated forms of squaraine dyes. The observation of this short-wavelength band, assigned to non-emissive $\mathrm{H}$-aggregate has already been observed for squaraines ${ }^{[35,38]}$ and their dimers, ${ }^{[17-18]}$ although the broadened red-shifted spectrum indicated that the aggregation of dyes within the endearment is more complex. Hydrophobic nature and $\pi$-stacking interactions within the adjacent squaraine units in aqueous media facilitates the $\mathrm{H}$-aggregation. However, the presence of multiple dye unites within the dendrimer may favour multiple aggregated forms, including those with lower excitation energy ( $J$-like aggregates). ${ }^{[39]}$ In this case, this dye-dye aggregation is probably realized through a hydrophobic collapse of the dendrimer bringing together SQ dyes in the dendrimer core. Some intermolecular aggregation of dendrimers cannot be totally excluded, especially in the case of more hydrophobic dendrimers SQ-tet and SQ-oct. The evidence for such aggregation is seen even in organic solvent for SQ-tet and $\mathbf{S Q}$-oct as shown in Figure $1 \mathrm{~A}$ (vide infra).

In fluorescence spectra, all the dyes in organic solvents displayed a single emission band $(639-659 \mathrm{~nm})$ with minimal solvatochromism (Figure 2A,B, Table 1, Figure S1). Generally, the fluorescence intensity and the quantum yield (Table 1) of all 

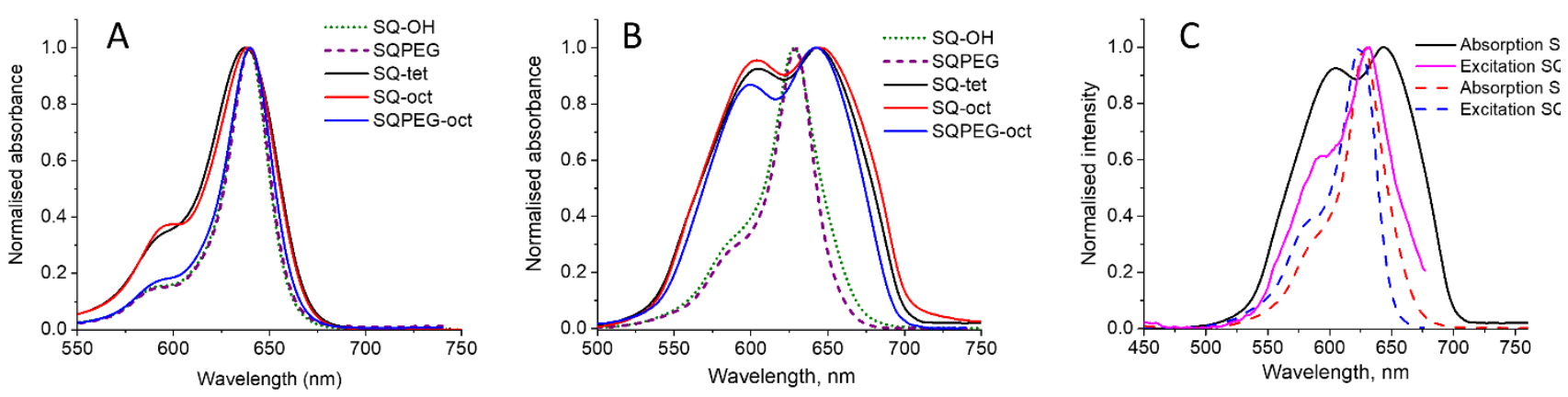

Figure 1. Absorption and fluorescence excitation properties of the squaraine dyes, tetramer and octamers. (A,B) Absorption spectra (normalized at its band maximum) of the dyes in dioxane (A) and water $(B)$. (C) Absorption and excitation $\left(\lambda_{e m}=685 \mathrm{~nm}\right)$ spectra of SQ-tet and SQ-OH in water. Concentration was adjusted to keep constant total SQ (monomer) concentration: $240 \mathrm{nM}$ for SQ-OH and SQPEG; $60 \mathrm{nM}$ for SQ-tet; $30 \mathrm{nM}$ for SQ-oct and SQPEG-oct.

the dyes decreased with the increase in solvent polarity from dioxane to water, which is typical for SQ dyes. ${ }^{[34 a, 40]}$ However, dendrimer dyes in water showed dramatic loss of emission (Figure 2B, Figure S1), with fluorescence quantum yields (QYs) systematically below $0.1 \%$ (Table 1 ). In line with the observations in the absorption spectra (Figure 1B), these results suggest that aggregation of dyes due to the dendrimer collapse in water leads to effective dye self-quenching. In addition, SQ-tet, SQ-oct and SQPEG-oct showed red shifted emission band around $685 \mathrm{~nm}$, in addition to the characteristic SQ emission band (Figure S3). Domination of this new red shifted band followed the order SQoct> SQ-tet> SQPEG-oct, which indicated that the hydrophobicity and steric crowdedness played a crucial role in observing new emission band in water. The excitation spectra of these dyes recorded at the new emission band $(685 \mathrm{~nm})$, showed broad band centred at $630-635 \mathrm{~nm}$ with

Table 1. Spectroscopic properties of all the compounds studied in this work. ${ }^{[a]}$

\begin{tabular}{|c|c|c|c|c|c|c|c|c|c|}
\hline \multirow{2}{*}{ Dye } & \multirow[b]{2}{*}{$\begin{array}{c}\varepsilon \text { in } \\
\text { Dioxane }\end{array}$} & \multicolumn{7}{|c|}{ QY (\%) } & \multirow{2}{*}{$\begin{array}{l}\tau \text { in } \\
\text { Diox } \\
\text { ane } \\
\text { (ns) }\end{array}$} \\
\hline & & $\begin{array}{l}\text { Diox } \\
\text { ane }\end{array}$ & $\begin{array}{l}\text { DM } \\
\text { SO }\end{array}$ & $\begin{array}{l}\text { DM } \\
\mathrm{F}\end{array}$ & $\begin{array}{l}\mathrm{EtO} \\
\mathrm{H}\end{array}$ & $\begin{array}{l}\mathrm{Me} \\
\mathrm{OH}\end{array}$ & $\begin{array}{l}\text { Wat } \\
\text { er }\end{array}$ & $\begin{array}{l}\text { Buff } \\
e^{\left[r^{[b]}\right.}\end{array}$ & \\
\hline SQ-OH & 328,000 & 58.7 & 27.9 & 20.4 & 22.1 & 11.2 & 5.1 & 2.5 & 1.70 \\
\hline $\begin{array}{l}\text { SQPE } \\
\text { G }\end{array}$ & 332,000 & 51.1 & 31.7 & 26.3 & 24.4 & 11.4 & 5.9 & 7.8 & 1.47 \\
\hline $\begin{array}{l}\text { SQPE } \\
\text { G-RGD }\end{array}$ & 320,000 & 27.4 & 26.9 & 20.7 & 16.5 & 8.9 & 0.77 & 0.91 & 1.34 \\
\hline SQ-tet & $1,150,000$ & 25.7 & 13.9 & 9.5 & 5.2 & 2.6 & 0.05 & 0.08 & 1.10 \\
\hline SQ-oct & $2,210,000$ & 2.6 & 2.2 & 2.0 & 1.3 & 0.70 & 0.03 & 0.04 & 0.72 \\
\hline $\begin{array}{l}\text { SQPE } \\
\text { G-oct }\end{array}$ & $2,320,000$ & 25.0 & 14.8 & 10.3 & 6.7 & 3.4 & 0.06 & 0.07 & 1.13 \\
\hline $\begin{array}{l}\text { SQPE } \\
\text { G-oct- } \\
\text { RGD }\end{array}$ & $2,050,000$ & 19.2 & 15.6 & 11.5 & 7.6 & 4.0 & 0.09 & 0.13 & 1.05 \\
\hline
\end{tabular}

[a] $\varepsilon$ is molar absorption coefficient in $\mathrm{M}^{-1} \cdot \mathrm{cm}^{-1}$; QY is fluorescence quantum yield; $\tau$ is a mean fluorescence lifetime; $\lambda_{\mathrm{ex}}=407 \mathrm{~nm}$ and $\lambda_{\mathrm{em}}$ monitored at its band maximum (ca. $650 \mathrm{~nm}$ ). [b] Phosphate buffer ( $\mathrm{pH}=7.4,20 \mathrm{mM}$ ) a significant short-wavelength shoulder at $595 \mathrm{~nm}$, previously assigned to the dye aggregates. This indicates that this new emission band originated from aggregated $S Q$ dyes in the dendrimer systems. However, the emission of these aggregates is rather low because of very low total QY of dendrimers in water (Table 1).

In non-polar dioxane, significant differences within dyes were also observed: monomeric dyes SQ-OH and SQPEG showed more than $50 \%$ QY, whereas for SQ-tet and SQ-oct QY reduced to 25.7 and $2.6 \%$, respectively (Table 1 ). The fluorescence lifetime also followed this trend: $\mathbf{S Q}-\mathbf{O H}>\mathbf{S Q}$-tet $>$ SQ-oct, which confirmed the possibility of self-quenching within the overcrowded SQ dyes in organic solvent, especially in SQ-oct. Interestingly, QY of PEG8-based octamer (SQPEG-oct) was ca. 10 times higher compared to SQ-oct, thus showing that longer and PEGylated linker ensures larger dye-dye distance for extended solvated form of the dendrimer in organic solvents. Conversely, in SQ-oct, the linker is too short, so that the dyes remain too close leading to their self-quenching. This explanation is also supported by the differences in the absorption spectra of SQ-oct and SQPEG-oct (Figure 1A). Indeed, significant short-wavelength shoulder in SQ-oct indicated some dye-dye interaction, whereas for SQPEG-oct it was lower, being close to the monomers. Remarkably, SQPEG-oct in water showed negligible fluorescence $(Q Y=0.06 \%)$ similar to the octamer without $P E G$ linkers (SQ-oct), showing that that this long PEG linker does not interfere with collapse of the dendrimer in water and preserves the aggregation-caused quenching of SQ dyes. The presence of inorganic salts in phosphate buffer saline did not significantly affect the observed low QY values in aqueous media.

To study fluorogenic properties of the dyes, we compared their QY in organic solvents vs water (Figure 2C). It is clear that all dendrimers drastically enhance their $Q Y$ in organic solvents, which is not the case of monomers. Then, we characterized optical properties of our probes in the water-dioxane mixtures, which allows gradual change in the solvent polarity. When a content of dioxane in water increased, the characteristic shortwavelength band assigned to aggregated forms in SQPEG-oct (Figure 2D) and other dendrimers (Figure S4-S5) decreased, while their main band shifted to the blue and sharpened. These changes were accompanied with strong gradual increase in the fluorescence intensity of the dendrimers (Figure 2E, Figure S4$\mathrm{S} 5$ ), in contrast to the monomers showing much lower 
A

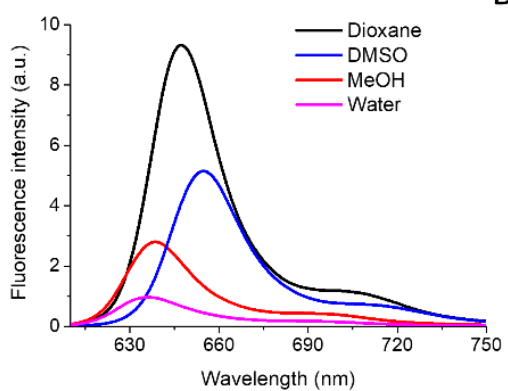

D

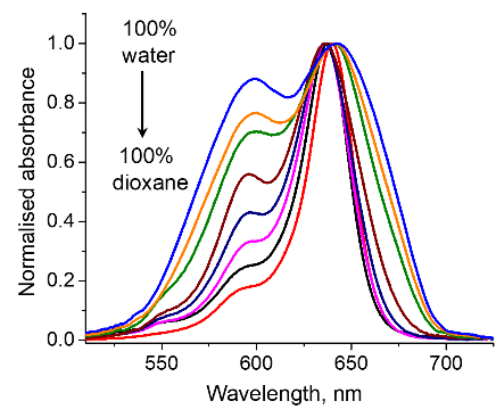

E

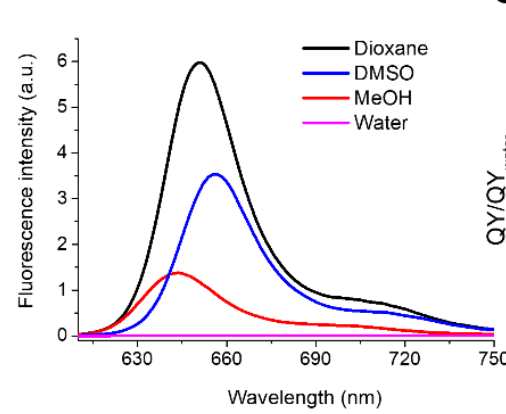

C
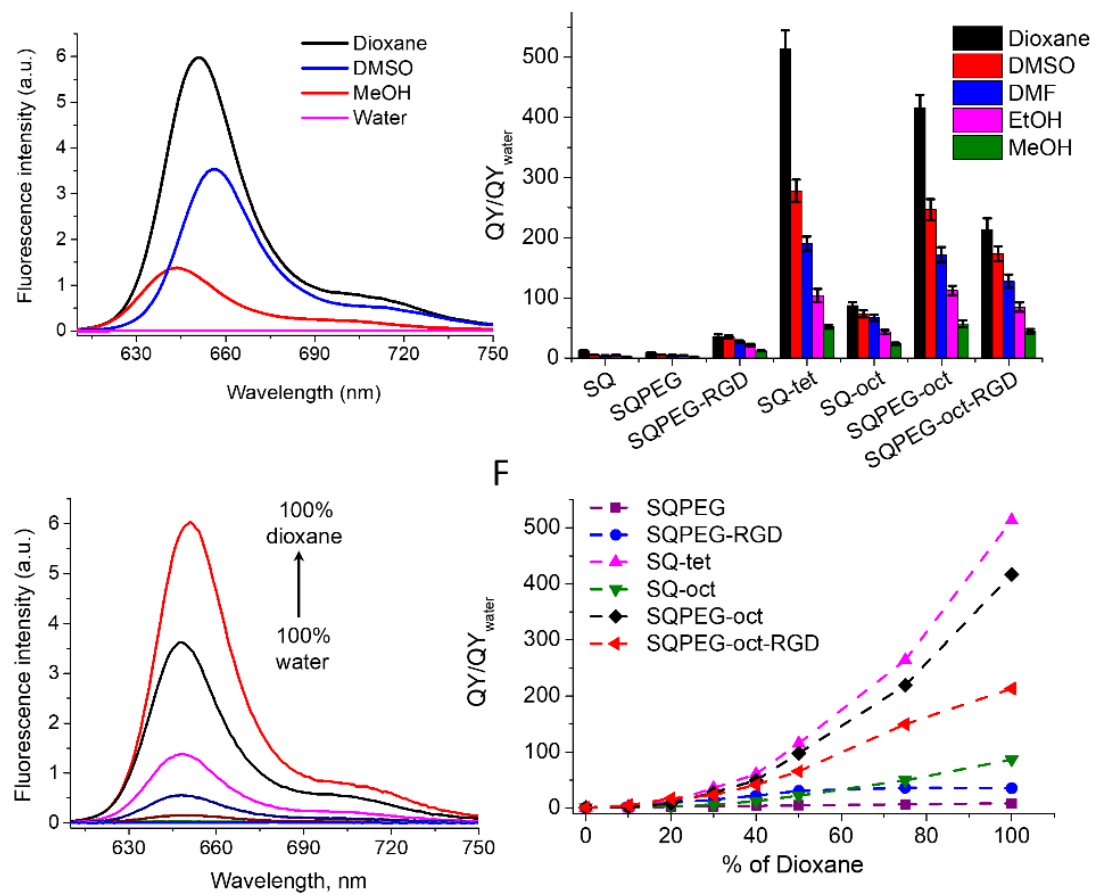

$\mathrm{F}$

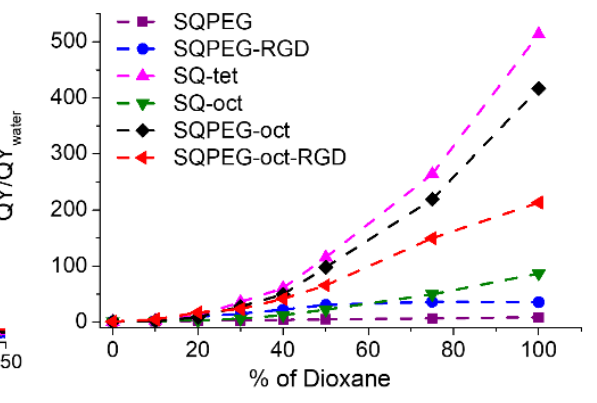

Figure 2. Solvent-dependent fluorescence and absorption properties of dyes. (A, B) Fluorescence spectra of monomer SQ-OH (A) dendrimer SQPEG-oct (B) in different solvents $\left(\lambda_{\mathrm{ex}}=600 \mathrm{~nm}\right)$. (C) Turn-on properties of all dyes studied in this work in various organic solvents (ratio of quantum yield in organic solvents to that in water $Q Y / Q Y_{\text {water }}$ ). (D,E) Absorption (D) and fluorescence (E) spectra of SQPEG-oct in water-dioxane mixtures $\left(\lambda_{\text {ex }}=600 \mathrm{~nm}\right)$; the content of dioxane in the mixture is $0,10,20,30,40,50,75,100 \%$. (F) Fluorogenic response (ratio of quantum yields) of all the dyes as a function of dioxane content in water-dioxane mixtures. Concentration was adjusted to keep constant total SQ (monomer) concentration: $240 \mathrm{nM}$ for SQ-OH, SQPEG; $60 \mathrm{nM}$ for SQ-tet; $30 \mathrm{nM}$ for SQ-oct, SQPEG-oct, SQPEG-oct-RGD.

fluorescence enhancement (Figure 2F, Figure S6). Thus, the gradual decrease in the solvent polarity decreased the aggregation-caused quenching of the fluorophores within the dendrimers, leading to their fluorogenic response. The largest fluorogenic effects were observed for SQ-tet and SQPEG-oct (Figure 2F), the latter being more promising due to the turn-on of 8 squaraine fluorophores (vs 4 in SQ-tet). Upon changing the solvent from water to dioxane SQPEG-oct displayed 416-fold increase in the fluorescence quantum yield (Figure 2F), which made this dendrimer an ideal platform for the development of fluorogenic probes for bio-relevant targets. Such fluorogenic nature should facilitate background-free cellular imaging under no-wash condition. Moreover, taking into account of the huge extinction coefficient of the octamer $\left(\sim 2,321,000 \mathrm{M}^{-1} \mathrm{~cm}^{-1}\right)$ and its good quantum yield in non-polar media ( $Q Y=25 \%$ in dioxane), this octamer module can be considered among the brightest fluorogenic molecule reported to date.

To explore the significance of octameric system in cellular imaging, $\alpha_{v} \beta_{3}$ integrin targeting cyclic RGDfK peptide was introduced in SQPEG-oct through click chemistry (Scheme 2) to yield SQPEG-oct-RGD (Figure 3A). A monomeric SQ dye RGD conjugate (SQPEG-RGD) was made for comparison (Scheme 2). The spectroscopic properties of the obtained SQPEG-oct-RGD conjugate were similar to those of the parent SQPEG-oct (Table 1 and Figure S1-S3). Indeed, in water the QY remained low, while in organic solvents it drastically increased. Gradual decrease of the solvent polarity in water-dioxane mixtures gave similar changes in the absorption and the fluorescence enhancement
(Figure S7). SQPEG-oct-RGD exhibited a turn-on response of 213-fold between water and dioxane (Table 1, Figure 2F). Slightly smaller turn-on effect SQPEG-oct-RGD compared to SQPEGoct is probably because of "buffering" effect of RGD peptide, which may reduce the variation of polarity in the surrounding of the octamer. On the other hand, monomeric SQPEG-RGD showed surprisingly low $Q Y$ in water, compared to $\mathbf{S Q}-\mathbf{O H}$ and SQPEG, because of intermolecular aggregation, proven by the absorption spectrum of SQPEG-RGD in water, showing a characteristic short-wavelength $\mathrm{H}$-aggregation band (Figure $\mathrm{S} 1$ ). In solvent mixtures, this band disappeared already at $10 \%$ dioxane (Figure S8), because of dye dis-aggregation, which was accompanied with increase in fluorescence intensity. Therefore, SQPEG-RGD displayed non-negligible 35-fold enhancement in QY between dioxane and water (Figure 2F, Table 1), but it was still much lower compared to that of the dendrimers.

Next we checked the possible nonspecific interactions and the resultant false turn-on fluorescence signal from the dyes in the presence of proteins and lipid membranes using: bovine serum albumin (BSA, the major component of serum) and large unilamellar lipid vesicles composed of dioleoylphosphatidylcholine (DOPC). SQPEG-oct-RGD showed 7 and 3-fold enhancement in the fluorescence quantum yield in the presence of BSA and DOPC vesicles, respectively (Figure 3B), which was rather weak compared to the 213-fold enhancement observed in apolar solvent. The effect of BSA and lipid vesicles was similar for other dendrimers without RGD, SQ-tet, SQ-oct and SQPEG-oct. Moreover, no significant changes 

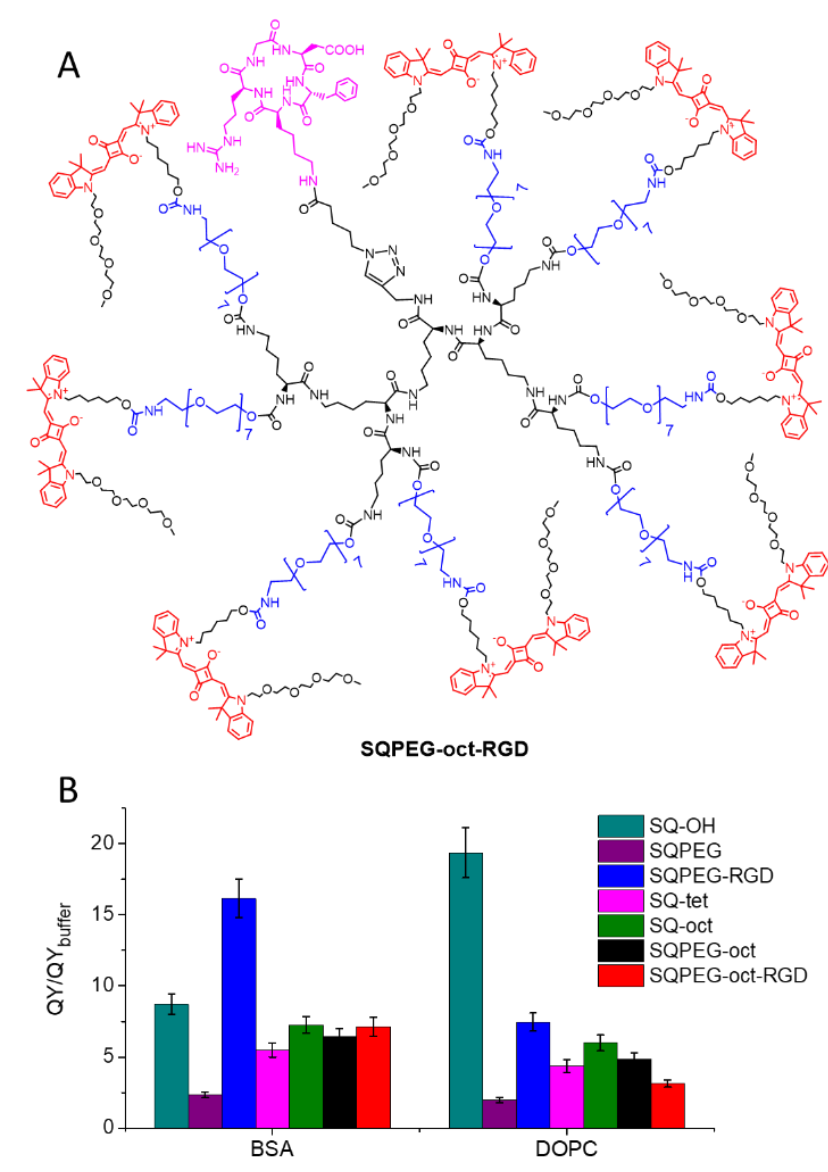

Figure 3. Structure of SQPEG-oct-RGD (A). Studies of non-specific interactions of all the dyes with BSA and lipid vesicles (composed of DOPC). Ratio of quantum yield in DOPC and BSA to that in phosphate buffer $(\mathrm{pH}=7.4$, $20 \mathrm{mM}$ ) (QY/QYbuffer) (B). Concentration of BSA is $20 \mu \mathrm{M}$ and DOPC is $200 \mu \mathrm{M}$.

in the absorption spectra were detected (Figure S9). On the other hand, monomeric SQPEG-RGD showed 16- and 7-fold enhancement for BSA and DOPC (Figure 3B), respectively, which was comparable to the 35 -fold fluorescence increase observed in non-polar dioxane. This non-specific fluorescence response was accompanied by decrease in the short-wavelength shoulder (Figure S9), indicating that BSA and DOPC vesicles disrupt dye aggregates, similarly to other solvents. Therefore, unlike dendrimer SQPEG-oct-RGD, this monomeric conjugate is strongly affected by the non-specific binding to proteins and lipid membranes, which could be detrimental for its applications as fluorogenic probe for specific imaging of membrane receptors.

\section{Cellular studies}

To demonstrate the selective integrin mediated cellular binding and uptake of RGD coupled probes, fluorescence imaging was performed on U-87 MG (glioblastoma) cells, which are known to overexpress $\alpha_{\mathrm{v}} \beta_{3}$ integrin receptor. ${ }^{[41]}$ Cells were individually incubated with SQPEG-oct-RGD, SQPEG-oct, SQPEG-RGD and SQPEG for various time periods at $37{ }^{\circ} \mathrm{C}$ and imaged by fluorescence microscopy without any washing step. Despite the low concentration used ( $3 \mathrm{nM})$, a bright red fluorescence with a granular pattern was observed in the cytoplasm for SQPEG-octRGD incubation after $1 \mathrm{~h}$ (Figure 4A), indicating an efficient cellular uptake of the probe. By contrast, the octamer without RGD ligand (SQPEG-oct) did not show any detectable fluorescence in cells (Figure $4 C$ ) suggesting the role of the RGD ligand in $\alpha_{v} \beta_{3}$ integrin-mediated intracellular uptake of probe. The difference in the signal was confirmed by a quantitative fluorescence intensity analysis (Figure S10). Time-dependence of cellular uptake of these two probes was then investigated to understand the non-specific cellular internalisation over the longer period of time. SQPEG-oct-RGD showed significant internalisation already at $30 \mathrm{~min}$ incubation time and the signal continued increasing over $2 \mathrm{~h}$ (Figure S11), whereas SQPEG-oct showed no visible internalisation up to $1 \mathrm{~h}$ incubation (Figure S12). However, after 2h, SQPEG-oct internalized to a small extent into the cells, which was visible with the 10-fold magnified intensity scale (Figure S12). Thus, it is reasonable to infer that the enhanced uptake of SQPEG-oct-RGD in cells compared to SQPEG-oct, can be ascribed to a receptor-mediated endocytosis owing to the overexpression of $\alpha_{v} \beta_{3}$ integrin receptor recognized by the RGD ligand. ${ }^{[42]}$ On the other hand, SQPEG-oct without the RGD ligand underwent much slower receptor-independent endocytosis observed only for the longer incubation times. To provide further support for the integrin-mediated cellular uptake of SQPEG-oct-RGD, a competition assay was conducted: U-87 MG cells were pre-treated with a large excess of free RGD ligand for 20 min prior to the incubation with SQPEG-oct-RGD (for 1h). Fluorescence images showed no appreciable fluorescence in the intracellular region (Figure 4B), which indicated competitive inhibition on the $\alpha_{v} \beta_{3}$ binding sites. These results indicated that the enhanced cellular uptake of SQPEG-oct-RGD in cancer cells is attributed to integrin-mediated endocytic pathway. Significant change in the cell morphology toward a rounder shape can also be noticed (Figure 4B), which is probably because the excess of RGD ligand inhibited $\alpha_{v} \beta_{3}$-controlled interaction of the cells with the surface.

To verify the energy dependence of integrin-mediated cellular uptake, the cells were incubated with SQPEG-oct-RGD probe at $4{ }^{\circ} \mathrm{C}$ for $1 \mathrm{~h}$. The cell showed very few red fluorescence dots (Figure S13), visible only with the 10-fold magnified intensity scale, indicating that the uptake of the probe is active, probably due to integrin-mediated endocytosis. Another key feature of SQPEGoct-RGD probe was the exceptionally low background observed despite not employing any washing step after the treatment with the probe (Figure 4A), probably because octamer is poorly emissive in the aqueous extracellular medium. As a result, the intensity ratio of the intracellular signal vs extracellular background was $\sim 15$. Thus, in the extracellular aqueous medium, our octameric probe, being in the collapsed self-quenched state, does not give significant fluorescence signal. After entering the intracellular environment through integrin mediated endocytosis, the octameric probe encounters more hydrophobic environment of endosomal/lysosomal membranes, which leads to the disaggregation of $\mathrm{SQ}$ units of the octamer and overall fluorescence turn on of the system.

Fluorescence imaging was also performed with the monomeric dye conjugate SQPEG-RGD, which showed some intracellular fluorescence signal after $1 \mathrm{~h}$ incubation (Fig. 4D). However, the lack of fluorogenecity was clearly visible from the strong fluorescence background, resulting in the signal-tobackground ratio for this probe around 1.8. Experiments at $4{ }^{\circ} \mathrm{C}$ 


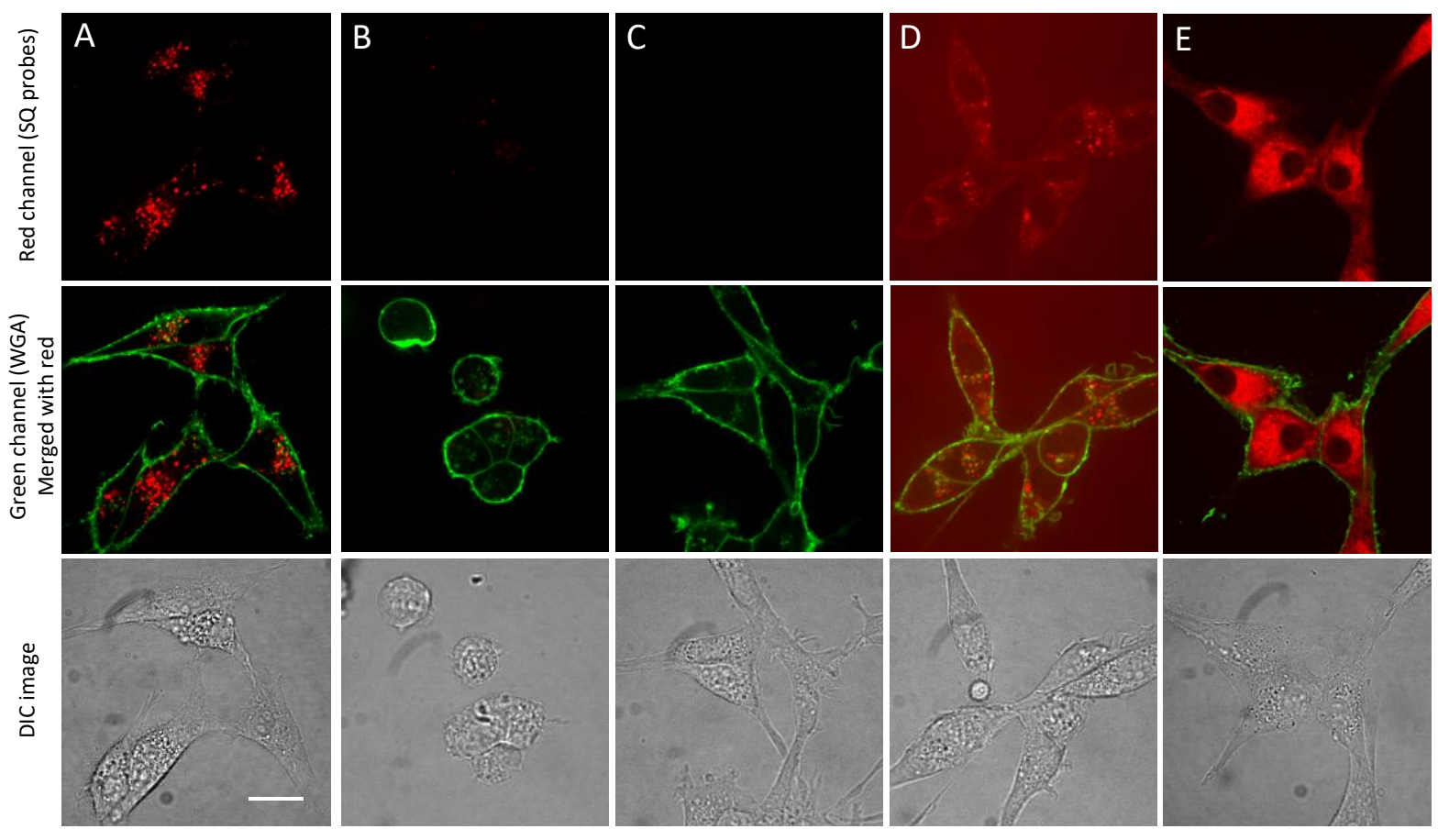

Figure 4. Fluorescence images of U-87 MG cells with SQ probes co-stained WGA-488 marker (50 nM). 1 hr incubation at $37^{\circ} \mathrm{C}$ with $3 \mathrm{nM}$ of SQPEG-oct-RGD (A); pre-incubation of cells with RGD ligand $(100 \mu \mathrm{M})$ at $22^{\circ} \mathrm{C}$ for 20 min prior to $1 \mathrm{hr}$ incubation at $37^{\circ} \mathrm{C}$ with $3 \mathrm{nM}$ of SQPEG-oct-RGD (B); $1 \mathrm{hr}$ incubation at $37^{\circ} \mathrm{C}$ with $3 \mathrm{nM}$ of SQPEG-oct (C); $1 \mathrm{hr}$ incubation at $37^{\circ} \mathrm{C}$ with $20 \mathrm{nM}$ of SQPEG-RGD (D); $1 \mathrm{hr}$ incubation at $37^{\circ} \mathrm{C}$ with $20 \mathrm{nM}$ of SQPEG (E). Spinning disk imaging mode was used; SQ probes and WGA marker were excited with 640 and $488 \mathrm{~nm}$ lasers, respectively, while emission was detected using $705 / 72$ and $530 / 30$ band-pass filters, respectively. Scale bar is $15 \mu \mathrm{m}$.

showed decreased intracellular signal of SQPEG-RGD (Figure S13), suggesting that this probe also internalized by active endocytosis pathway. Finally, control squaraine dye without RGD ligand (SQPEG) incubated with cells at room temperature displayed much higher fluorescence signal than the SQPEG-RGD conjugate (Figure 4E, Figure S10), which was distributed homogeneously over the entire cytoplasm. The observed stronger signal for non-targeted probe underlines an additional disadvantage of the monomeric system, as it can internalize nonspecifically into the cells probably because of small size and insufficient hydrophilicity.

\section{Conclusion}

To achieve detection and imaging of biomolecular targets in cells with high sensitivity and imaging contrast, a fluorescent probe should present high brightness together with fluorogenic (turn-on) response when bound to the target. In this work, we aimed to address a fundamental problem of limited brightness of organic dyes and at the same time to implement robust mechanism of fluorescence turn-on triggered by changes in the environment polarity after the target recognition. To this end, we introduced a concept of a fluorogenic dendrimer, that undergoes polarity-dependent fluorescence turn-on due to the intramolecular collapse/expansion: in polar aqueous media its collapsed form ensures efficient dye self-quenching, while in the non-polar medium its expanded form separates the dyes, providing fluorescence light up. A series of dendrimers bearing four and eight squaraine dye units as well as their monomeric analogues were synthesized. The absorption and fluorescence studies revealed effective aggregation-caused quenching of all dendrimers in aqueous media. In non-polar media, they exhibited dramatic fluorescence enhancement, owing to the disaggregation of the dyes within the dendrimer. However, when the eight dyes were grafted to the dendrimer through a short linker, even in nonpolar media the dye self-quenching was still observed probably because of insufficient spacing within dyes. This problem was overcome by introducing sufficiently long PEG(8) linkers between the dyes and the dendrimer core, which allowed us to obtain fluorogenic dendrimer displaying $>400$-fold fluorescence enhancement from polar water (collapsed OFF state) and nonpolar dioxane (expanded ON state). Taking into account its high extinction coefficient $\left(\sim 2,300,000 \mathrm{M}^{-1} \mathrm{~cm}^{-1}\right)$ and good quantum yield in non-polar media (25\%), this dendrimer can be considered as the brightest environment-sensitive fluorogenic molecule reported to date. Indeed, it is much brighter than environmentsensitive probes based on a single fluorophore, where the extinction coefficient typically ranges from 10,000 to $100,000 \mathrm{M}^{-1}$ $\mathrm{cm}^{-1}$. [2a] It is also much brighter than the fluorogenic dye dimers we reported previously, ${ }^{[17]}$ as in the present systems we employed 4-fold more dyes within the same probe. The conjugate of the optimized octameric dendrimer with cyclic RGD ligand preserved its fluorogenic properties in organic solvents and showed minimal non-specific response to proteins and lipid membranes. The obtained conjugate, SQPEG-oct-RGD, was applied for imaging $\alpha_{\mathrm{v}} \beta_{3}$ integrin receptor, overexpressed on the surface of cancer ( $U$ $87 \mathrm{MG}$ ) cells. We expected that the ligand-receptor binding would decrease the local polarity of the dendrimer environment, in line with previous data on solvatochromic and fluorogenic dimer probes for oxytocin GPCR, ${ }^{[14 a, 17,19,34 a]}$ and biotin receptor. ${ }^{[18]}$ Fluorescence microscopy of U-87 MG cells incubated for $1 \mathrm{~h}$ with 
SQPEG-oct-RGD probe revealed strong intracellular signal despite the use of very low probe concentrations ( $3 \mathrm{nM})$. Multiple control experiments suggested that the fluorogenic dendrimerRGD conjugate underwent integrin-mediated endocytosis: (i) dendrimer without the RGD ligand did not show significant signal in the cells; (ii) the signal of the probe can be attenuated by competition with free cyclic RGD; (iii) at low temperature $\left(4^{\circ} \mathrm{C}\right)$ no internalization of the probe was observed. Importantly, the new fluorogenic dendrimer probe enabled receptor-specific imaging of cancer cells with strong signal to background ( 15), in contrast to corresponding monomer, which exhibited low fluorescence contrast $(\sim 1.8)$ because of significant background in the medium. Moreover, its monomeric analogue without RGD was unable to provide receptor-specific cell imaging, due to the strong nonspecific internalization with much higher intracellular signal than the monomeric RGD conjugate. The newly developed fluorogenic dendrimer occupies a unique position among the existing fluorescent probes: it is in a "golden middle" between fluorescent dyes and nanoparticles taking advantage from both systems. On one hand, it remains very small, because it is essentially a molecular probe. On the other hand, it exhibits exceptional brightness similarly to fluorescent nanoparticles. In fact, its brightness $\left(\sim 2,300,000 \mathrm{M}^{-1} \mathrm{~cm}^{-1} \times 0.25=575,000 \mathrm{M}^{-1} \mathrm{~cm}^{-1}\right)$ is similar to those of luminescent quantum dots, which are well known bright nanoparticles used for bioimaging. ${ }^{[43]}$ Combination of small size, high brightness and fluorogenic response to the environment makes them advantageous compared to existing molecular and nanoparticles probes. Therefore, we expect that the developed environment-sensitive fluorogenic octamer and its design concept will result in a new generation of bright probes for imaging biomolecular targets in live cells with superior temporal and spatial resolution as well as for ultrasensitive detection of cancer biomarkers in clinical diagnostics.

\section{Acknowledgements}

This work was supported by the European Research Council ERC Consolidator grant BrightSens 648528. P.A. acknowledges Senior Postdoctoral Fellowship grant sponsored under Government of India, MHRD-RUSA 2.0 (No. F.24-51/2014- U, Policy (TN-Multi-Gen), dated 09.10.2018). We acknowledge the Service de Chimie Analytique (SCA) for NMR and mass spectral analyses and Monique Dontenwill and Sophie Martin for providing U-87 MG cells.

\section{Conflicts of interest}

There are no conflicts to declare.

Keywords: fluorescent probes $\cdot$ dendrimers $\cdot$ aggregation $\bullet$ fluorogenic response $\bullet$ integrin receptor

[1] a) A. Fernández, M. Vendrell, Chem. Soc. Rev. 2016, 45 1182; b) L. Wang, M. S. Frei, A. Salim, K. Johnsson, J. Am. Chem. Soc. 2019, 141, 2770.

[2] a) A. S. Klymchenko, Accounts Chem. Res. 2017, 50, 366; b) A. Nadler, C. Schultz, Angew. Chem. Int. Ed. 2013, 52, 2408.
[3] a) J. Chan, S. C. Dodani, C. J. Chang, Nat. Chem. 2012, 4, 973; b) X. Ji, K. Ji, V. Chittavong, R. E. Aghoghovbia, M. Zhu, B. Wang, J. Org. Chem. 2017, 82, 1471; c) G. Lukinavičius, L. Reymond, K. Umezawa, O. Sallin, E. D'Este, F. Göttfert, H. Ta, S. W. Hell, Y. Urano, K. Johnsson, J. Am. Chem. Soc. 2016, 138, 9365.

[4] a) M. N. Bongiovanni, et al., Nat. Commun. 2016, 7, 13544; b) S. Moon, R. Yan, S. J. Kenny, Y. Shyu, L. Xiang, W. Li, K. Xu, J. Am. Chem. Soc. 2017, 139, 10944; c) E. Kozma, P. Kele, Org. Biomol. Chem. 2019, 17, 215; d) G. Lukinavicius, et al., Nat. Methods 2014, 11, 731; e) D. I. Danylchuk, S. Moon, K. Xu, A. S. Klymchenko, Angew. Chem. Int. Ed. 2019, 58, 14920.

[5] X. Li, X. Gao, W. Shi, H. Ma, Chem. Rev. 2014, 114, 590.

[6] a) J. C. Carlson, L. G. Meimetis, S. A. Hilderbrand, R. Weissleder, Angew. Chem. Int. Ed. 2013, 52, 6917; b) L. G. Meimetis, J. C. Carlson, R. J. Giedt, R. H. Kohler, R. Weissleder, Angew. Chem. Int. Ed. 2014, 53, 7531; c) H. Wu, S. C. Alexander, S. Jin, N. K. Devaraj, J. Am. Chem. Soc. 2016, 138, 11429 .

[7] C. Reichardt, Chem. Revi. 1994, 94, 2319.

[8] A. P. Demchenko, K. C. Tang, P. T. Chou, Chem. Soc. Rev. 2013, 42, 1379.

[9] Z. R. Grabowski, K. Rotkiewicz, W. Rettig, Chem. Revi. 2003, 103, 3899.

[10] M. K. Kuimova, Phys. Chem. Chem. Phys. 2012, 14, 12671.

[11] D. D. Su, C. L. Teoh, L. Wang, X. G. Liu, Y. T. Chang, Chem. Soc. Rev. 2017, 46, 4833.

[12] a) K. R. Raghupathi, J. Guo, O. Munkhbat, P. Rangadurai, S. Thayumanavan, Acc Chem Res 2014, 47, 2200; b) D. Zhai, W. Xu, L. Zhang, Y. T. Chang, Chem. Soc. Rev. 2014, 43, 2402.

[13] J. Mei, N. L. C. Leung, R. T. K. Kwok, J. W. Y. Lam, B. Z Tang, Chem. Revi. 2015, 115, 11718.

[14] a) I. A. Karpenko, R. Kreder, C. Valencia, P. Villa, C. Mendre, B. Mouillac, Y. Mély, M. Hibert, D. Bonnet, A. S. Klymchenko, ChemBioChem 2014, 15, 359; b) I. A. Karpenko, Y. Niko, V. P. Yakubovskyi, A. O. Gerasov, D. Bonnet, Y. P. Kovtun, A. S. Klymchenko, J. Mater. Chem. C 2016, 4, 3002; c) P. Ashokkumar, A. H. Ashoka, M. Collot, A. Das, A. S. Klymchenko, Chem. Commun. 2019, 55, 6902; d) K. Mizusawa, Y. Ishida, Y. Takaoka, M. Miyagawa, S. Tsukiji, I. Hamachi, J. Am. Chem. Soc. 2010, 132, 7291; e) K. Mizusawa, Y. Takaoka, I. Hamachi, J. Am. Chem. Soc. 2012, $134,13386$.

[15] a) R. Weissleder, C. H. Tung, U. Mahmood, A. Bogdanov, Jr., Nat Biotechnol 1999, 17, 375; b) J. Hu, G. Zhang, S. Liu, Chem. Soc. Rev. 2012, 41, 5933.

[16] A. Okamoto, Chem. Soc. Rev. 2011, 40, 5815.

[17] I. A. Karpenko, M. Collot, L. Richert, C. Valencia, P. Villa, Y. Mély, M. Hibert, D. Bonnet, A. S. Klymchenko, J. Am. Chem. Soc. 2015, 137, 405.

[18] K. T. Fam, M. Collot, A. S. Klymchenko, Chem. Sci. 2020, 11, 8240.

[19] L. Esteoulle, F. Daubeuf, M. Collot, S. Riché, T. Durroux, D. Brasse, P. Marchand, I. A. Karpenko, A. S. Klymchenko, D. Bonnet, Chem. Sci. 2020, 11, 6824.

[20] F. Bouhedda, K. T. Fam, M. Collot, A. Autour, S. Marzi, A. Klymchenko, M. Ryckelynck, Nat. Chem. Biol. 2020, 16, 69.

[21] C. C. Lee, J. A. MacKay, J. M. J. Frechet, F. C. Szoka, Nat. Biotechnol. 2005, 23, 1517.

[22] a) I. Oesterling, K. Mullen, J. Am. Chem. Soc. 2007, 129, 4595; b) F. C. De Schryver, T. Vosch, M. Cotlet, M. Van der Auweraer, K. Mullen, J. Hofkens, Accounts Chem. Res. 2005, 38, 514; c) V. Balzani, P. Ceroni, S. Gestermann, C. Kauffmann, M. Gorka, F. Vogtle, Chem. Commun. 2000, 853.

[23] V. Balzani, G. Bergamini, P. Ceroni, E. Marchi, New Journal of Chemistry 2011, 35, 1944.

[24] Y. Y. Cheng, L. B. Zhao, Y. W. Li, T. W. Xu, Chem. Soc. Rev. 2011, 40, 2673.

[25] a) C. Szent-Gyorgyi, B. F. Schmidt, J. A. J. Fitzpatrick, M. P. Bruchez, Journal of the American Chemical Society 2010, 132, 11103; b) B. Liu, T. T. T. Dan, G. C. Bazan, Advanced Functional Materials 2007, 17, 2432. 
[26] a) M. D. Pierschbacher, E. Ruoslahti, Nature 1984, 309, 30; b) C. J. Avraamides, B. Garmy-Susini, J. A. Varner, Nat. Rev. Cancer 2008, 8, 604.

[27] E. C. da Silva, M. Dontenwill, L. Choulier, M. Lehmann, Cancers 2019, 11, 27

[28] J. S. Desgrosellier, D. A. Cheresh, Nat. Rev. Cancer 2010, 10, 9.

[29] a) M. Pfaff, K. Tangemann, B. Müller, M. Gurrath, G. Müller, H. Kessler, R. Timpl, J. Engel, J. Biol. Chem. 1994, 269, 20233; b) S. Zitzmann, V. Ehemann, M. Schwab, Cancer Res. 2002, 62, 5139.

[30] a) M. H. Lee, J. Y. Kim, J. H. Han, S. Bhuniya, J. L. Sessler, C. Kang, J. S. Kim, J. Am. Chem. Soc. 2012, 134, 12668; b) Y. Cheng, C. Sun, X. Ou, B. Liu, X. Lou, F. Xia, Chem. Sci. 2017, $8,4571$.

[31] X. Ma, J. Jia, R. Cao, X. Wang, H. Fei, J. Am. Chem. Soc. 2014, 136, 17734

[32] a) Z. Fan, Y. Chang, C. Cui, L. Sun, D. H. Wang, Z. Pan, M. Zhang, Nat. Commun. 2018, 9, 2605; b) E. Polo, T. T. Nitka, E. Neubert, L. Erpenbeck, L. Vuković, S. Kruss, ACS Appl. Mater. Interfaces 2018, 10, 17693; c) G. Feng, J. Liu, R. Liu, D. Mao, N. Tomczak, B. Liu, Adv. Sci. 2017, 4, 1600407; d) N. Depalo, et al., ACS Appl. Mater. Interfaces 2017, 9, 43113; e) M. Goutayer, S. Dufort, V. Josserand, A. Royere, E. Heinrich, F. Vinet, J. Bibette, J. L. Coll, I. Texier, Eur. J. Pharm. Biopharm. 2010, 75, 137.

[33] a) A. Ajayaghosh, Accounts Chem. Res. 2005, 38, 449; b) S. Sreejith, P. Carol, P. Chithra, A. Ajayaghosh, Journal of Materials Chemistry 2008, 18, 264.

[34] a) I. A. Karpenko, A. S. Klymchenko, S. Gioria, R. Kreder, I. Shulov, P. Villa, Y. Mely, M. Hibert, D. Bonnet, Chem. Commun. 2015, 51, 2960; b) L. I. Markova, E. A. Terpetschnig, L. D. Patsenker, Dyes and Pigments 2013, 99 , 561.

[35] H. Chen, M. S. Farahat, K.-Y. Law, D. G. Whitten, J. Am. Chem. Soc. 1996, 118, 2584.

[36] E. Arunkumar, A. Ajayaghosh, J. Daub, J. Am. Chem. Soc. 2005, 127, 3156.

[37] F. Ponsot, W. Shen, P. Ashokkumar, E. Audinat, A. S. Klymchenko, M. Collot, ACS Sensors 2017, 2, 1706.

[38] V. Grande, F. Doria, M. Freccero, F. Würthner, Angew. Chem. Int. Ed. 2017, 56, 7520.

[39] a) G. Chen, H. Sasabe, W. Lu, X.-F. Wang, J. Kido, Z. Hong, Y. Yang, J. Mater. Chem. C 2013, 1, 6547; b) F. Wurthner, T. E. Kaiser, C. R. Saha-Moller, Angew. Chem. Int. Ed. 2011, 50, 3376.

[40] P. Salice, J. Arnbjerg, B. W. Pedersen, R. Toftegaard, L. Beverina, G. A. Pagani, P. R. Ogilby, J. Phys. Chem. A 2010 114, 2518.

[41] a) S. Monferran, N. Skuli, C. Delmas, G. Favre, J. Bonnet, E. Cohen-Jonathan-Moyal, C. Toulas, Int. J. Cancer 2008, 123, 357; b) D. Moncelet, V. Bouchaud, P. Mellet, E. Ribot, S. Miraux, J. M. Franconi, P. Voisin, PLoS One 2013, 8, e82777.

[42] M. Li, W. Zhang, B. Wang, Y. Gao, Z. Song, Q. C. Zheng, Int. J. Nanomedicine 2016, 11, 5645.

[43] U. Resch-Genger, M. Grabolle, S. Cavaliere-Jaricot, R. Nitschke, T. Nann, Nat. Methods 2008, 5, 763. 


\section{Entry for the Table of Contents}

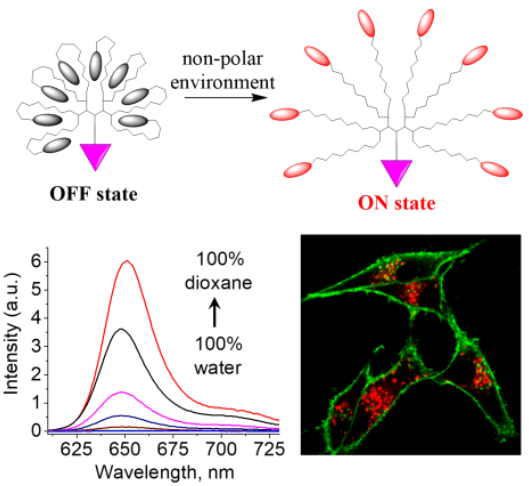

Fluorogenic dendrimer probe for imaging membrane receptors have been developed. It combines eight squaraine dyes that undergo polarity-dependent aggregation-disaggregation within the dendrimer, resulting in OFF-ON fluorescence response to a biomolecular target. It enables integrin-specific imaging of cancer cells with high signal-to-background ratio. 